\title{
Galvanizing medical students in the administration of influenza vaccines: the Stanford Flu Crew
}

This article was published in the following Dove Press journal:

Advances in Medical Education and Practice

I July 2015

Number of times this article has been viewed

\author{
Rachel E Rizal',* \\ Rishi P Mediratta ${ }^{1, *}$ \\ James Xie' \\ Swetha Kambhampati' \\ Kelsey Hills-Evans' \\ Tamara Montacute' \\ Michael Zhang' \\ Catherine $\mathrm{Zaw}^{2}$ \\ Jimmy $\mathrm{He}^{2}$ \\ Magali Sanchez ${ }^{2}$ \\ Lauren Pischel' \\ 'Stanford University School \\ of Medicine, Stanford, CA, USA; \\ ${ }^{2}$ Stanford University, Stanford, \\ CA, USA \\ *These authors contributed equally \\ to this work
}

Correspondence: Rishi P Mediratta Stanford University School of Medicine, Li Ka Shing Building, 3rd Floor, 291 Campus Drive Rm LK3C02, Stanford, CA 94305, USA Fax +I 6507257855

Email rishimd@stanford.edu

\begin{abstract}
Many national organizations call for medical students to receive more public health education in medical school. Nonetheless, limited evidence exists about successful servicelearning programs that administer preventive health services in nonclinical settings. The Flu Crew program, started in 2001 at the Stanford University School of Medicine, provides preclinical medical students with opportunities to administer influenza immunizations in the local community. Medical students consider Flu Crew to be an important part of their medical education that cannot be learned in the classroom. Through delivering vaccines to where people live, eat, work, and pray, Flu Crew teaches medical students about patient care, preventive medicine, and population health needs. Additionally, Flu Crew allows students to work with several partners in the community in order to understand how various stakeholders improve the delivery of population health services. Flu Crew teaches students how to address common vaccination myths and provides insights into implementing public health interventions. This article describes the Stanford Flu Crew curriculum, outlines the planning needed to organize immunization events, shares findings from medical students' attitudes about population health, highlights the program's outcomes, and summarizes the lessons learned. This article suggests that Flu Crew is an example of one viable service-learning modality that supports influenza vaccinations in nonclinical settings while simultaneously benefiting future clinicians.
\end{abstract}

Keywords: immunizations, vaccine delivery, vaccinations

\section{Background}

Consensus exists about the need to improve population health training for medical students. The Association of American Medical Colleges (AAMC), the Institute of Medicine (IOM), and the Liaison Committee on Medical Education (LCME) have developed recommendations that call for more public health education in US medical schools. ${ }^{1-3}$ All physicians are part of a public health system and consequently must receive adequate training in and exposure to public health. ${ }^{4}$ Nonetheless, $20 \%$ of medical students in the US report receiving inadequate training in public health. ${ }^{5}$ Medical students feel that there are ways to improve population health curricula and want more opportunities to engage with local communities. ${ }^{6}$

The IOM, AAMC, and LCME advocate that physicians-in-training must be exposed to public health concepts and skills. Specifically, all medical students should be taught about clinical and community preventive services. ${ }^{4,7}$ LCME has added public health components to the requirements needed to become a physician. ${ }^{1}$

There is limited evidence about population-based immunization campaigns led by medical students. ${ }^{8,9}$ In this article, we highlight a medical student organization called the 
Stanford Flu Crew in which medical students gain practical experiences in administering influenza vaccinations and learn about preventive health services. We describe the origin and mission, program description, vaccination outcomes, and medical student outcomes.

\section{Flu Crew origin and mission}

The Stanford Flu Crew began in 2001 when an adjunct faculty member at the Stanford University School of Medicine approached several first-year Stanford medical students with the opportunity to provide influenza vaccines. The physician, who specialized in occupational health, inspired medical students to provide 20 free flu vaccinations to farm workers in 2001. Over the last 11 years, Flu Crew has administered thousands of free flu vaccines. To our knowledge, the Stanford Flu Crew is the largest influenza prevention program of any medical school in the country. Flu Crew's mission is to immerse tomorrow's doctors in population-based health promotion and bring vaccinations to the doorsteps of communities. Flu Crew creates opportunities for medical students to provide immunizations in the community while addressing population health needs in underserved areas. Additionally, Flu Crew has received institutional support because the curriculum trains all first-year medical students in vaccine administration.

\section{Program description Governance}

Flu Crew's team is lead by two second-year medical student co-directors, two first-year medical student co-coordinators, two medical student education directors, and a medical director. The medical director provides clinical information about the administration of vaccines, provides medical opinion about any legal issues, and serves as the main supervising faculty member at flu clinics. The co-directors and coordinators oversee all organizational aspects of the program, including: organizing immunization clinics, delivering vaccines, and establishing partnerships with organizations. Finally, the education directors are responsible for creating online modules, updating training materials, and conducting training sessions for vaccinators.

\section{Vaccine supplies}

Various university and community partners contribute vaccines and supplies. All influenza vaccines are provided at no cost to patients and are paid by Flu Crew's partners: Stanford's Student Health Center, Stanford's Employee Health, a farm in the Central Valley, and the Santa Clara County Public Health Department.

\section{Recruiting vaccinators}

The majority of first-year medical students at Stanford volunteer to provide flu shots to the community. Medical students are trained to administer vaccines during September, which corresponds to the beginning of the influenza season and the first quarter of medical school.

\section{Partnerships}

Flu Crew has established strong partnerships with the School of Medicine, occupational health, campus health centers, the county health department, churches, free clinics, and homeless shelters. Flu Crew provides free vaccines by partnering with specific health institutions that are responsible for the health of a segment of the population. At the University, Flu Crew is part of a steering committee consisting of students and occupational health workers, which organizes on campus immunization events. Additionally, Flu Crew's partnership with Santa Clara Public Health Department increases the county's access to providing low-income communities with vaccines.

\section{Training}

Before providing flu shots, vaccinators complete a threestep training process. First, students watch online video modules to acquire knowledge about the influenza virus and to gain proficiency in answering patients' questions about the flu vaccine. After watching the modules, students complete a quiz that assesses their understanding. Second, volunteers attend a 2-hour Flu Crew Training session, where they observe a practical demonstration of an intramuscular injection. This is modeled and practiced by injecting saline into oranges. Finally, all medical students attend a vital skills training session as part of the first-year curriculum for learning clinical skills. Under the guidance of a physician, students practice intramuscular injections on one another. By the end of the training, Flu Crew expects students to have knowledge about various aspects of vaccines and vaccine protocol (Table 1).

\section{Organizing events}

Before each influenza season, Flu Crew receives legal clearance from Stanford's Risk Management Department. Medical students coordinate immunization events. Flu Crew tries to schedule its events when medical students are available, such as class-free days, weekends, and evenings. Events are not scheduled before exams to ensure greatest participation by medical students. For each community event listed in Table 2, a student leader is recruited to organize the event. 
Table I Learning objectives for the Stanford Flu Crew curriculum

\begin{tabular}{|c|}
\hline Knowledge \\
\hline Each student should be able to describe \\
\hline Brief history of the influenza virus \\
\hline Mortality and morbidity associated with influenza \\
\hline Function and classification of hemagglutinin and neuraminidase proteins \\
\hline Classic symptoms of an influenza infection and an influenza-like illness \\
\hline Diagnosis of influenza \\
\hline Preventing the spread of influenza \\
\hline Effectiveness of the influenza vaccine \\
\hline Types of influenza vaccines \\
\hline Risk and benefits of influenza vaccines \\
\hline Target population for seasonal influenza vaccine \\
\hline Contraindications to the live and inactivated influenza vaccines \\
\hline Process for administering a vaccine \\
\hline Virus strains that are represented in the latest influenza vaccine \\
\hline Equipment necessary for a safe and effective immunization station \\
\hline Guillain-Barré syndrome and how it relates to influenza \\
\hline Reporting needle stick injuries \\
\hline Reporting severe adverse reactions \\
\hline Skills \\
\hline Each student should be able to \\
\hline $\begin{array}{l}\text { Prepare a clean and safe immunization station that minimizes needle } \\
\text { stick injuries }\end{array}$ \\
\hline Load vaccine into syringes to minimize needle stick injuries \\
\hline Be familiar with the influenza immunization consent procedures \\
\hline Build rapid rapport with patients \\
\hline $\begin{array}{l}\text { Administer intramuscular injections using the Dart-Aspirate-Inject-Box } \\
\text { method }\end{array}$ \\
\hline Counsel patients who feel nauseous during the immunization \\
\hline $\begin{array}{l}\text { Counsel patients who have received the influenza vaccine in } \\
\text { previous years }\end{array}$ \\
\hline Work in an interdisciplinary team \\
\hline Attitudes \\
\hline Each student should be able to \\
\hline Appreciate the importance of immunizations in population health \\
\hline $\begin{array}{l}\text { Learn about challenges different patient populations face when } \\
\text { accessing immunizations }\end{array}$ \\
\hline Provide a public health service as a part of a health care team \\
\hline
\end{tabular}

The student leader is responsible for publicizing the event, transporting vaccine supplies to the clinic, setting up immunization stations, directing patient flow during events, and documenting the vaccine cold chain. Approximately six to ten vaccinators are recruited for each immunization clinic. For every six vaccinators, Flu Crew vaccinates approximately 100 individuals per hour.

\section{Publicity}

Flu Crew employs various channels of communication in order to create demand for flu vaccines. Each year, email messages that outline the vaccination events, locations, and times are sent to undergraduate and graduate students. Flu Crew publicizes the details of immunization events on a website that is promoted through social media and newspaper articles.
Table 2 Flu Crew's community partners

\section{Stanford Campus}

Flu Crew works with Stanford University's Vaden Student Health and Occupational Health to provide free flu vaccines annually to undergraduate students, graduate students, faculty members, and employees.

Churches

Flu Crew serves two churches in the Diocese of San Jose, California. Several hundred members attend each church, which are powerful community centers for its large Hispanic population.

\section{Shelters}

Flu Crew partners with several homeless shelters in San Jose. Some patients are low-income or struggle with drug abuse and addiction. Gender-specific shelters also welcome single mothers and their children. Student-run free clinics

The Arbor Free Clinic and the Pacific Free Clinic are two Stanford student-run clinics that offer basic health care and referral services to the underserved in the South Bay Area. Students are exposed to a diverse patient population, including immigrants, low-income individuals, uninsured citizens, and the homeless. The facility frequently offers translation services in Spanish, Vietnamese, Chinese, as well as many other languages as needed.

\section{Farms}

Flu Crew immunizes at a farm located in Central Valley, California. Vaccines are purchased by the company and are offered to its several thousand workers and the workers' families.

Furthermore, Flu Crew sends representatives to each undergraduate residential dorm to inform students about the vaccination events. Paper flyers are also posted in strategic locations around campus. Stanford undergrads reported in a postvaccination exit survey that emails and flyers, respectively, were the most common methods to learn about immunization events. For community sites, publicity for events at churches, farms, and free clinics is coordinated through the leader at the respective organization. Announcements and flyers are the main modes of publicity at these locations.

\section{Methods}

Ethical approval was not required as The Stanford University institutional review board (IRB) deemed that both the Flu Crew program and its evaluations are exempt from IRB review because the Flu Crew program is a teaching/educational activity rather than a research study.

At each clinic, we tallied the number of individuals vaccinated. The number of immunizations prior to 2010 was not able to be collected. We conducted 25 semi-structured interviews with medical students to learn how Flu Crew has affected students' attitudes about population health. Participants were first- or second-year medical students at Stanford University School of Medicine and were interviewed after the 2012 vaccination period. All 47 Flu Crew members were contacted by email to participate in the study. 
Twenty-five students responded and were contacted for a phone interview. A list of question prompts was used to initiate open discussion about population health. Participants were asked about their experience with Flu Crew, how the experience affected their understanding of population health and preventive health services, and how Flu Crew enriched their medical education. All interviews were recorded. Textual data were analyzed manually using a data matrix for predefined topics as well as emerging themes. Comments were analyzed using grounded theory and content analysis. Saturation of themes was achieved. Common themes and illustrative quotes are presented below. Medical students identified several areas in which Flu Crew furthered their medical education, clinical experience, and knowledge about public health.

\section{Flu vaccination outcomes}

Flu Crew provides many flu vaccinations each fall. In 2010, 2011, 2012, and 2013, Flu Crew administered 3,056, 3,997, 4,830, and 5,165 vaccinations, respectively. Figure 1 shows the number of vaccinations provided on campus and in the community. Over the course of its 12-year history, Flu Crew has become a successful organization that has helped establish Flu Crew chapters at UCSF in 2011 and UC Davis in 2012. The Stanford Flu Crew has developed a toolkit that guides medical students from other universities through a step-by-step process to start their own chapters.

\section{Medical student outcomes Improving medical education}

One of the themes identified in medical student interviews was the way in which Flu Crew became a valuable part of students' medical education because the immunization clinics provided them with early patient interaction.

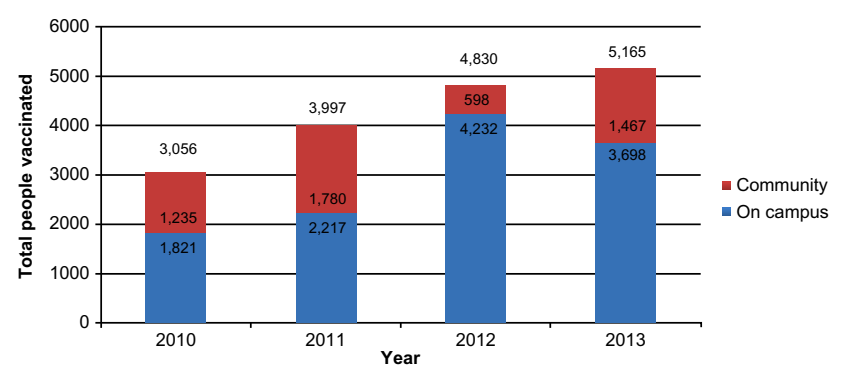

Figure I Number of Flu Vaccines Administered On Campus and in the Community by Flu Crew, 2010-2013.

Notes: On campus includes students, faculty members, and employees who were vaccinated on Stanford University's campus. Community includes individuals who were vaccinated at churches, shelters, farms, libraries, and other community centers.
"Flu Crew gave me one of the first opportunities to interact with real patients in the community and was the first medical procedure I ever did. It has really given me the basics and foundation for how to communicate well with patients, provide them medical services they need, and advocate for them."

"As a physician, it will be imperative that I understand my role in both promoting public health through preventative initiatives as well as responding to the individual questions and concerns from my patients."

Other students commented that they were able to develop their bedside manner while administering vaccines and responding to patients' questions.

\section{Addressing vaccination myths}

Medical student interviews revealed that Flu Crew taught students how to overcome common vaccination myths and address common vaccine misunderstandings.

"My experiences with Flu Crew will help me better prepare for public health interventions that I will conduct in the future. After realizing how resistant to vaccines many people are, I'll now set more realistic goals for future projects and plan strategies to address misinformation before encountering it in the field."

"My time with Flu Crew has given me the opportunity to talk to people in the community and better understand their ideas about the flu and vaccinations. I never realized how much misinformation exists, so it has been good to address common vaccine myths."

Medical students learned about vaccination myths and became more aware about misinformation surrounding influenza vaccines. Importantly, the training empowered students to educate the public and dispel misconceptions.

\section{Importance of partnerships}

Medical students reported that Flu Crew's partnerships with the community helped tackle some of the challenges surrounding public health issues.

\footnotetext{
"One of the most interesting parts of Flu Crew so far has been seeing how various community stakeholders can come together to make a difference in population health. Our event was a collaboration between the homeless shelter who advertised the event and allowed us to use their space, the county who provided the vaccines, and the Flu Crew team who provided the manpower to make it happen."
} 
"My experience in leading the Stanford Flu Crew provided me with first-hand insights into how public health programs impact populations. In comparison to the number of people we could vaccinate at a clinic, partnering with the community around us allowed us to deliver flu vaccines to thousands of people."

The Stanford Flu Crew model integrates partnerships with the university, a county health system, homeless shelters, student-run free clinics, and the medical school to provide immunizations to the underserved. By partnering with various organizations, students appreciated how more immunizations could be provided in non-traditional medical settings.

\section{Public health challenges}

Medical students described the ways in which Flu Crew taught them about the challenges involved with achieving herd immunity and how to systematically design public health interventions.

"Working with the Flu Crew has helped me gain a better understanding of how difficult it is to implement preventative interventions. You have to vaccinate such a high percentage of individuals in a community to achieve herd immunity. Working with Flu Crew has shown me how difficult this can be, even in small, confined communities like homeless shelters and farms."

"The lessons I have learned through Flu Crew will enable me to pursue population health interventions in a systematic fashion as a future physician. Being exposed to the conceptual framework for designing and executing a public health intervention will be important for me."

By involving future physicians in the implementation of an influenza immunization campaign, Flu Crew gave medical students tools they could use in executing public health programs.

\section{Population health programs}

Finally, medical students reported that Flu Crew taught them about an innovative healthcare delivery model for population health.

"Flu Crew is a fantastic way to not only understand the socioeconomic barriers of public health campaigns like influenza vaccination, but also to see stellar examples of how to overcome these barriers. For example, the campaigns at the student-run free clinics have consistently had a difficult time recruiting people in the community to come to the clinic for large, single-day vaccination events. Taking the time away from family or work to come into clinic, or finding transportation, are extra steps and potential reasons why turnout is so low. One easy way to overcome this problem is to bring the vaccinations to where people congregate - especially to where people work. Flu Crew does just this by going to mushroom farms to vaccinate the farmers and to churches to vaccinate the members."

"Today's world of medicine is headed in the direction of preventive health care. The more risk factors we reduce, the earlier we diagnose, and the more we educate our patients, the more effective we will be in preventing or treating the diseases, whether it be influenza and its complications, diabetes, or coronary artery disease. By vaccinating various sectors of the population, we have helped prevent influenza in the underserved population that is more vulnerable and prevent complications from influenza such as pneumonia."

Students better understood that providing flu vaccinations and educating individuals about influenza contributed to reducing morbidity and mortality. Flu Crew represents one model in which community-based health care can provide medical students with knowledge and experience in public health issues.

\section{Discussion}

Flu Crew is a unique student-led organization that addresses challenges with flu vaccination campaigns as well as population health education in the medical school curriculum. It is novel because it integrates partnerships with a university, county health system, and medical school to provide immunizations. The experience of Stanford's Flu Crew program suggests that a student organization can collaborate with many stakeholders to teach students and provide immunizations in many community settings. Engaging preclinical students in vaccine administration is one way to provide early clinical experience, develop bedside manner, gain confidence in a simple medical procedure, and address critical population health needs.

Flu Crew has played an important role in increasing influenza vaccination rates. The $\mathrm{CDC}$ estimates that the national coverage of influenza vaccination among adults greater than 18 years was 39\% in 2012. ${ }^{10}$ Most flu vaccinations are administered in health clinics, but Flu Crew provides services in nontraditional settings, increasing access to preventive services. ${ }^{11-13}$ The Flu Crew experience is consistent with the Sickness Prevention Achieved through Regional Collaboration 
model, where adult screenings and immunizations are delivered at senior housing facilities, fire stations, and schools. ${ }^{14}$ Flu Crew contributed to meeting one of the national objectives of the US Health People initiative, while advancing medical students' role in public health. ${ }^{15}$

By immunizing in community settings, Flu Crew increases access to vaccinations and offers medical students a unique opportunity to obtain service-learning opportunities in nonclinical settings. The majority of service-learning modalities in medical schools are centered on the treatment of illnesses at student-run free clinics. ${ }^{16}$ Flu Crew's strong community partnerships allow students to deliver health care to where individuals eat, pray, live, and work.

Flu Crew contributes to the AAMC's objective that medical students participate in population health improvement strategies ${ }^{7}$ and the Clinical Prevention and Population Health Curriculum Framework's objective of integrating population health into medical school curricula. ${ }^{17}$ Flu Crew has worked with the medical school faculty to integrate its training into the medical school curriculum. It has therefore received institutional support and can serve as an example for other student-led organizations at academic medical centers. Medical students serve as agents of change who implement preventive services. ${ }^{18}$ Flu Crew's success supports the growing literature of how population health can be integrated in medical education by organizing electives and courses, ${ }^{19,20}$ supporting student-run clinics, ${ }^{21}$ and designing population health projects. ${ }^{22,23}$

Because of Flu Crew's positive impact with vaccinating the community and improving population health within medical education, the Flu Crew model has been replicated at two other academic medical centers. Expanding Flu Crews to academic medical centers presents an opportunity to contribute to national pandemic preparedness efforts. The Flu Crew model can be used to address the recruitment and training challenges during an influenza pandemic. The education directors created online modules so the public can access the Flu Crew's curriculum, which is freely available via the Khan Academy, an online educational organization (https:// www.khanacademy.org/partner-content/stanford-medicine/ stanford-influenza).

\section{Limitations}

Flu Crew has a few limitations. First, the program is reliant upon substantial volunteer student and faculty involvement. Students' participation at immunization clinics is dependent upon classes, exams, and extracurricular activities. Furthermore, it is challenging to recruit physicians to supervise students during immunization events. The number of immunization events organized by Flu Crew is based upon students' schedules and the faculty members' availability. Second, Flu Crew experiences a high turnover rate among vaccinators. To combat this problem, continuity of leadership ensures that a high proportion of students are recruited each year. Third, our success is limited by the vaccines and supplies that are donated by our partners. Flu Crew does not receive funding, but provides free flu shots to the community by institutional support and partnering with organizations that are invested in the health of the community. Finally, the data in our paper are susceptible to selection bias because only students who responded by email were interviewed. Other programs can institute more rigorous pre- and posttraining surveys.

\section{Conclusion}

Medical student influenza programs provide students with exposure to delivering preventive public health services while simultaneously addressing health disparities in communities. The experience from Stanford suggests that Flu Crew can be expanded nationally. Medical schools should consider establishing Flu Crews in order to engage students in population health within medical education. Furthermore, the Flu Crew model can be used to increase the coverage of other vaccines. Future directions include integrating health education about vaccines into vaccination events.

\section{Acknowledgments}

Special thanks to the following Stanford medical students, faculty, and staff for their leadership and continuous support: Ira Friedman, MD and Nancy Masunaga, RN of Vaden Student Health Center; Jordan Firestone, MD and Imee Diego DuBose of Occupational Health Center; Jennefer Yoon, Pharm D, Assistant Director of Pharmacy, Santa Clara County Public Health Department; Preetha Basaviah, MD, FACP of the Stanford University School of Medicine; Rhonda McClinton-Brown at the Office of Community Health; Arbor and Pacific Free Clinics; Patrick O'Callahan, MD of Occupational Health; Douglas Shenson, MD, MPH of the Yale School of Medicine and the Founder of Vote and Vax; Santa Clara County Board of Supervisors, Liz Kniss, RN, and the Registrar of Voters; Stanford physicians: Marina Martin, MD, MPH, Neil Gesundheit, MD, MPH, Peter Kao, MD, PhD, and Lars Osterberg, MD, MPH. The Flu Crew curriculum was developed by students and physicians Walter Newman 
Jr, MD, Patricia Fast, MD, PhD, and Patrick O'Callahan, MD, MPH. Much appreciation to the founder of Flu Crew, Walter Newman Jr, MD. and Dean Charles Prober, MD.

\section{Disclosure}

All of the authors are part of the Flu Crew Leadership Team. The authors report no conflicts of interest in this work.

\section{References}

1. Liaison Committee on Medical Education. Functions and Structure of a Medical School: Standards for Accreditation of Medical Education Programs Leading to the MD Degree. Chicago, IL: Liaison Committee on Medical Education; 2013. Available from: http://www.lcme.org/ publications/functions.pdf. Accessed December 15, 2014.

2. Institute of Medicine Committee on Behavioral and Social Sciences in Medical School Curricula; Cuff PA, Vanselow NA, editors. Improving Medical Education: Enhancing the Behavioral and Social Science Content of Medical School Curricula. Washington, DC: National Academies Press; 2004.

3. Expert Panel on Cultural Competence Education for Students in Medicine and Public Health. Cultural Competence Education for Students in Medicine and Public Health: Report of an Expert Panel. Washington, DC: Association of American Medical Colleges and Association of Schools of Public Health; 2012. Available from: https://members.aamc. org/eweb/upload/Cultural\%20Competence\%20Education_revisedl.pdf. Accessed December 15, 2014.

4. Institute of Medicine; Hernandez LM, Munthali AW, editors. Training Physicians for Public Health Careers. Washington, DC: National Academies Press; 2007.

5. Association of American Medical Colleges. Medical School Graduation Questionnaire: 2012 All Schools Summary Report. Washington, DC: Association of American Medical Colleges; 2012. Available from: https:// www.aamc.org/download/300448/data/2012gqallschoolssummaryrepor t.pdf. Accessed December 15, 2014.

6. Tyler IV, Hau M, Buxton JA, et al. Canadian medical students' perceptions of public health education in the undergraduate medical curriculum. Acad Med. 2009;84(9):1307-1312.

7. Maeshiro R, Johnson I, Koo D, et al. Medical education for a healthier population: reflections on the Flexner Report from a public health perspective. Acad Med. 2010;85(2):211-219.

8. Simpson SA, Long JA. Medical student-run health clinics: important contributors to patient care and medical education. J Gen Intern Med. 2007;22(3):352-356.

9. Penfold RB, Rusinak D, Lieu TA, Shefer A, Messonnier M, Lee GM. Financing and systems barriers to seasonal influenza vaccine delivery in community settings. Vaccine. 2011;29(52):9632-9639.
10. Centers for Disease Control and Prevention. Flu Vaccination Coverage, United States, 2011-2012 Influenza Season. Atlanta, GA: Centers for Disease Control and Prevention; 2012. Available from: http://www. cdc.gov/flu/pdf/fluvaxview/vax-coverage-1112estimates.pdf. Accessed December 15, 2014.

11. Ogden LL, Richards CL, Shenson D. Clinical preventive services for older adults: the interface between personal health care and public health services. Am J Public Health. 2012;102(3):419-425.

12. Shenson D, Anderson L, Slonim A, Benson W. Vaccinations and preventive screening services for older adults: opportunities and challenges in the USA. Perspect Public Health. 2012;132(4):165-170.

13. Shenson D, Adams M. The Vote and Vax program: public health at polling places. J Public Health Manag Pract. 2008;14(5):476-480.

14. Shenson D, Benson W, Harris AC. Expanding the delivery of clinical preventive services through community collaboration: the SPARC model. Prev Chronic Dis. 2008;5(1):A20.

15. Healthy People 2020 [webpage on the Internet]. Washington, DC: US Department of Health and Human Services; 2010. Available from: http://healthypeople.gov/2020/topicsobjectives2020/default.aspx. Accessed December 15, 2014.

16. Reynolds HY. Free medical clinics: helping indigent patients and dealing with emerging health care needs. Acad Med. 2009;84(10):1434-1439.

17. Allan J, Barwick TA, Cashman S, et al. Clinical prevention and population health: curriculum framework for health professions. Am J Prev Med. 2004;27(5):471-476.

18. Maeshiro R. Responding to the challenge: population health education for physicians. Acad Med. 2008;83(4):319-320.

19. Lang F, Ferguson KP, Bennard B, Zahorik P, Sliger C. The Appalachian Preceptorship: over two decades of an integrated clinical-classroom experience of rural medicine and Appalachian culture. Acad Med. 2005;80(8):717-723.

20. Finkelstein JA, McMahon GT, Peters A, Cadigan R, Biddinger P, Simon SR. Teaching population health as a basic science at Harvard Medical School. Acad Med. 2008;83(4):332-337.

21. Landy DC, Gorin MA, O'Connell MT. Student-led rural health fairs: attempting to improve medical education and access to health care. South Med J. 2011;104(8):598-603.

22. Chamberlain LJ, Wang NE, Ho ET, Banchoff AW, Braddock CH 3rd, Gesundheit N. Integrating collaborative population health projects into a medical student curriculum at Stanford. Acad Med. 2008;83(4): 338-344.

23. Kerkering KW, Novick LF. An enhancement strategy for integration of population health into medical school education: employing the framework developed by the Healthy People Curriculum Task Force. Acad Med. 2008;83(4):345-351.
Advances in Medical Education and Practice

\section{Publish your work in this journal}

Advances in Medical Education and Practice is an international, peerreviewed, open access journal that aims to present and publish research on Medical Education covering medical, dental, nursing and allied health care professional education. The journal covers undergraduate education, postgraduate training and continuing medical education

\section{Dovepress}

including emerging trends and innovative models linking education, research, and health care services. The manuscript management system is completely online and includes a very quick and fair peer-review system. Visit http://www.dovepress.com/testimonials.php to read real quotes from published authors. 